\title{
Effects of Replacing Fishmeal by Raw or Lactobacillus acidophilus-Fermented Soybean Meal on Growth, Intestinal Digestive and Immune-Related Enzyme Activities, Morphology, and Microbiota in Turbot (Scophthalmus maximus $\mathrm{L}_{\text {.) }}$
}

\author{
Chaoqun Li, ${ }^{1}$ Yuan Tian, ${ }^{2,3}$ Lei Wang, ${ }^{4}$ Beili Zhang $\mathbb{D}^{1},{ }^{1}$ and Qinyuan Ma ${ }^{1}$ \\ ${ }^{1}$ School of Life Sciences and Medicine, Shandong University of Technology, Zibo 255000, China \\ ${ }^{2}$ Key Laboratory of Aquaculture Nutrition and Feed, Ministry of Agriculture, Ocean University of China, Qingdao 266003, China \\ ${ }^{3}$ Key Laboratory of Mariculture (Ministry of Education), Ocean University of China, Qingdao 266003, China \\ ${ }^{4}$ School of Ocean, Yantai University, Yantai 264005, China
}

Correspondence should be addressed to Beili Zhang; zhangbeili@sdut.edu.cn and Qinyuan Ma; qyma@sdut.edu.cn

Received 4 December 2021; Revised 7 January 2022; Accepted 21 January 2022; Published 17 February 2022

Academic Editor: Adri n J. Hern ndez

Copyright (C) 2022 Chaoqun Li et al. This is an open access article distributed under the Creative Commons Attribution License, which permits unrestricted use, distribution, and reproduction in any medium, provided the original work is properly cited.

\begin{abstract}
This study was performed to investigate the fermentation efficiency of Lactobacillus acidophilus and compare the effects of dietary soybean meal (SM) or L. acidophilus-fermented SM (LASM) on turbot. Two hundred and seventy juvenile turbots (13.50 $\pm 0.13 \mathrm{~g})$ were randomly divided into three treatments fed with a fishmeal-based diet (CNT) and two experimental diets with $45 \%$ fishmeal protein replaced by SM or LASM for 8 weeks. The results showed that fermentation significantly improved the essential amino acid profile, increased the lactic acid content, and reduced the antinutritional factor level in SM. Inferior growth of fish was observed in the SM group after the feeding trial, while the LASM group exhibited comparable performance to the CNT group. Activities of intestinal digestive enzymes (trypsin and diastase) and immune-related enzymes (alkaline phosphatase, acid phosphatase, and lysozyme) decreased significantly in the SM group, while no significant reduction was found in the LASM group compared to the CNT group. Dietary LASM alleviated SM-induced intestinal pathological disruption with higher villus and normal lamina propria width. Dietary LASM positively regulated the intestinal microbiota, making the overall profile more coherent with that in the CNT group. Spearman's correlation analysis revealed that the altered intestinal microbiota was closely linked to the digestive enzyme activities. Collectively, this study indicated that $L$. acidophilus fermentation significantly improved the nutritional quality of SM and relieved SM-induced adverse effects on turbot, in terms of growth, intestinal digestive and immune-related enzyme activities, morphology, and microbiota.
\end{abstract}

\section{Introduction}

Achieving effective substitution of fishmeal in aquafeed is a key element in the sustainable development of aquaculture. The soaring price and limited resources of fishmeal have prompted researchers to accelerate the exploration of highquality alternative protein sources [1]. Among various alternative protein sources, soybean meal (SM) has been of special concern, owing to its high protein level, low cost, abundance, and stable supply [2]. Nevertheless, several unfavorable factors including the presence of antinutritional fac- tors (ANFs), unbalanced essential amino acids, and poor palatability restricted the inclusion of SM in aquafeed [3, 4]. Substituting fishmeal with SM at an excessive level generally impairs growth and digestive function and even triggers SM-induced enteropathy (SBMIE) in fish [5-8]. Therefore, exploring cost-effective means to reduce or eliminate the SM-induced adverse effects on fish has long been a focus of research into aquaculture.

Several techniques including mechanical, thermal, or zymologic treatment have been applied to SM processing and quality improvement; however, most of them have 
drawbacks such as nutrient loss, high cost, and uncontrollable processes [9]. Microbial fermentation is considered a cost-effective and reliable technique with which to improve the quality of SM because of its superior abilities in the degradation of ANFs and the increase of bioactive factors including probiotics and beneficial metabolites [10-12]. The microorganism used for fermentation is the main determinant of fermentation product quality, and so far, most species used for SM fermentation belong to Bacillus spp., Aspergillus spp., and Lactobacillus spp. [10, 13, 14]. Lactobacillus acidophilus as a recognized probiotic is widely distributed in the intestines of humans and animals [15]. L. acidophilus has exhibited multiple functions in inhibiting intestinal pathogenic bacteria, activating the immune system, relieving digestive disorder, etc. [16, 17]. Previous research confirmed the beneficial influences of dietary L. acidophilus supplementation in diets for several fish species. Hoseinifar et al. [18] found that dietary L. acidophilus improved growth performance and stress resistance and beneficially modulated the intestinal microbiota of black swordtail (Xiphophorus helleri). Hosseini et al. [19] indicated that dietary L. acidophilus affected immune- and appetiterelated genes expression as well as skin mucus protein profile in gold fish (Carassius auratus gibelio). Hassaan et al. [20] reported that dietary $L$. acidophilus significantly improved the gut morphology and antioxidant enzyme activity in Nile tilapia (Oreochromis niloticus). Nevertheless, studies regarding the efficiency of L. acidophilus fermentation in improving SM quality and assessment of L. acidophilus-fermented SM (LASM) in aquafeed have yet to be performed.

Turbot (Scophthalmus maximus L.) is a valuable marine carnivorous flatfish species in terms of aquaculture; it possesses high requirements on protein level $\left(\sim 500 \mathrm{~g} \mathrm{~kg}^{-1}\right.$ diet $)$ and exhibits high sensitivity to differences in protein source $[21,22]$. Previous studies have indicated that high SM diet can easily cause growth impairment and intestine dysfunction in turbot $[23,24]$. In current study, the efficiency of $L$. acidophilus fermentation in improving the nutritional profile of SM was estimated. Also, a feeding trial was performed to compare the influences of dietary SM or LASM on turbot, in terms of growth and feed utilization performance, intestinal digestive and immune-related enzyme activities, morphology, and microbiota.

\section{Materials and Methods}

2.1. Animal Ethics Statement. All animal care and treatment procedures were performed in accordance with the Guidelines for Care and Use of Laboratory Animals of Shandong University of Technology. The ethical treatment of animals used in this study was approved by the Animal Welfare Ethics Committee of Shandong University of Technology (LGD 18-01-03).

2.2. Microorganism and Solid-State Fermentation. The Lactobacillus acidophilus used for solid-state fermentation was obtained from BeNa Culture Collection. Defatted SM was provided by Great-Seven Biotech. Co. Ltd. (Qingdao,
China). L. acidophilus strains were propagated twice in MRS broth (Haibo, Qingdao) at $37^{\circ} \mathrm{C}$ for $16 \mathrm{~h}$ without agita-

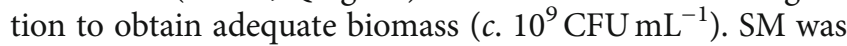
soaked with distilled water (solid-liquid ratio $=1: 1 \mathrm{~g} \mathrm{~mL}^{-1}$ ) and autoclaved in a steam tank (model HX14G-1, Shanghai, China) at $105^{\circ} \mathrm{C}$ for $20 \mathrm{~min}$. After cooling down, the SM were inoculated with L. acidophilus $\left(\sim 1 \times 10^{8} \mathrm{CFU} \mathrm{g}^{-1}\right.$ dry $\mathrm{SM})$, sufficiently mixed, then fermented in an incubator at $37^{\circ} \mathrm{C}$ for $48 \mathrm{~h}$. After fermentation, the LASM was ovendried until the moisture content was below $10 \%$, ground to a fine particle diameter ( 80 mesh), and stored at $4^{\circ} \mathrm{C}$ before use. Both the SM and LASM samples were collected for nutritional profile analysis which were performed in triplicate.

2.3. Experimental Diets. In the present study, three isonitrogenous and isoenergetic experimental diets were formulated (Table 1): a fishmeal-based diet as the positive control (CNT group), a SM-based diet as the negative control (SM group, with $45 \%$ fishmeal protein replaced by SM), and a LASMbased diet (LASM group, with 45\% fishmeal protein replaced by LASM). FM, SM, and LASM were used as the major protein sources. Fish oil was used as the major lipid source. Lysine and methionine were supplemented to meet the requirements of juvenile turbot. All ingredients were ground to pass an 80-mesh screen, mixed gradually, and blended with oil and water. Pellets $(3 \mathrm{~mm} \times 4 \mathrm{~mm})$ were made automatically by pellet-making machine and dried for $12 \mathrm{~h}$ in a ventilated oven at $50^{\circ} \mathrm{C}$. All diets were stored at $-20^{\circ} \mathrm{C}$ until used.

2.4. Experimental Fish and Feeding Trial. Juvenile turbots were transported from Yongfeng Aquatic Product Co. Ltd. (Laizhou, China) to a flowing water culturing facility in $\mathrm{Yi}$ Haifeng Aquatic Product Co. Ltd. (Qingdao, China). Fish were acclimated to the system and fed with commercial feed for 2 weeks prior to the feeding trial. After $24 \mathrm{~h}$ fasting, 270 hardy turbots of similar size $(13.5 \pm 0.13 \mathrm{~g})$ were distributed into nine $300 \mathrm{~L}$ tanks (three replicates per group, 30 fish per tank). Fish were fed to visual satiation twice a day (8:00 a.m. and 7:00 p.m.) for 8 weeks. After $40 \mathrm{~min}$ of feeding, the residual feed was put out and drying weighed for subsequent calculation of feed intake. The aquatic environment parameters were determined by automatic monitoring system and maintained as water temperature $18-21^{\circ} \mathrm{C}$, salinity 24 $27 \mathrm{~g} \mathrm{~L}^{-1}$, ammonia-nitrogen $<0.2 \mathrm{mgL}^{-1}$, dissolved oxygen $6-8 \mathrm{mgL}^{-1}$, and nitrite $<0.1 \mathrm{mg} \mathrm{L}^{-1}$ during the feeding trial.

2.5. Sample Collection. At the end of the feeding trial, fish in each tank were group weighted and counted to determine the growth parameters. After $24 \mathrm{~h}$ fasting and anesthetized through immersion (eugenol $1: 10000$ ), blood samples from six fish per tank were collected from the caudal vein using sterile $1 \mathrm{~mL}$ syringes and stored in an ice-cold anticoagulant tube. Plasma was separated by centrifugation (Eppendorf Centrifuge $5427 \mathrm{R}$ ) at $6000 \mathrm{~g}$ for $5 \mathrm{~min}$ at $4^{\circ} \mathrm{C}$. Then, the distal intestines of three fish were separated, rinsed carefully with PBS and fixed in paraformaldehyde solution (4\%) for histological evaluation. The entire intestines of the 
TABle 1: Formulation and proximate composition of the experimental diets.

\begin{tabular}{|c|c|c|c|}
\hline & \multicolumn{3}{|c|}{ Treatments } \\
\hline & CNT & SM & LASM \\
\hline \multicolumn{4}{|l|}{ Ingredients ( $\mathrm{g} \mathrm{kg}^{-1}$ diet $)$} \\
\hline Fishmeal $^{\mathrm{a}}$ & 600.0 & 330.0 & 330.0 \\
\hline Soybean meal & 0.0 & 378.7 & 0.0 \\
\hline Fermented soybean meal & 0.0 & 0.0 & 360.9 \\
\hline Wheat meal & 242.8 & 59.1 & 83.7 \\
\hline Wheat gluten meal & 21.2 & 63.4 & 56.6 \\
\hline Fish oil & 46.0 & 72.0 & 72.0 \\
\hline Lysine & 0.0 & 3.9 & 3.9 \\
\hline Methionine & 0.0 & 2.9 & 2.9 \\
\hline Vitamin premix ${ }^{\mathrm{b}}$ & 20.0 & 20.0 & 20.0 \\
\hline Mineral premix ${ }^{c}$ & 10.0 & 10.0 & 10.0 \\
\hline Others ${ }^{\mathrm{d}}$ & 60.0 & 60.0 & 60.0 \\
\hline \multicolumn{4}{|l|}{ Proximate composition } \\
\hline Energy (kJ g ${ }^{-1}$ diet) & 19.76 & 20.13 & 20.28 \\
\hline Crude protein ( $\mathrm{g} \mathrm{kg}^{-1}$ diet) & 501.2 & 498.9 & 501.8 \\
\hline Crude lipid ( $\mathrm{g} \mathrm{kg}^{-1}$ diet$)$ & 129.8 & 131.3 & 132.2 \\
\hline
\end{tabular}

Note: CNT: the control diet containing 60\% fishmeal; SM: $45 \%$ fishmeal protein replaced by the soybean meal; LASM: $45 \%$ fishmeal protein replaced by the $L$. acidophilus-fermented soybean meal. a Supplied by Great Seven Bio-Tech (Qingdao, China), crude protein, $716.2 \mathrm{mgg}^{-1}$; crude lipid, $97.8 \mathrm{mgg}^{-1}$. ${ }^{\mathrm{b}}$ Vitamin premix $\left(\mathrm{g} \mathrm{kg}^{-1}\right.$ diet): VA, 0.032; VE, 0.24; VK, 0.01; VD3, 0.005; VB1, 0.025; VB2, 0.045; VB6, 0.02; VB12, 0.01 ; D-calcium pantothenate, 0.06 ; amine nicotinic acid, 0.20 ; folic acid, 0.02; VH, 0.06; mesoinositol, 0.80; VC (35\%), 2.00; microcrystalline cellulose, 16.473. ${ }^{\mathrm{c}}$ Mineral premix $\left(\mathrm{g} \mathrm{kg}^{-1}\right.$ diet): $\mathrm{MgSO} 4 \cdot 7 \mathrm{H} 2 \mathrm{O}, 1.20$; $\mathrm{FeSO} 4 \cdot \mathrm{H} 2 \mathrm{O}, 0.08 ; \mathrm{CoCl} 2 \cdot 6 \mathrm{H} 2 \mathrm{O}, 0.05 ; \mathrm{ZnSO} 4 \cdot \mathrm{H} 2 \mathrm{O}, 0.05 ; \mathrm{MnSO} 4 \cdot$ $\mathrm{H} 2 \mathrm{O}, 0.045 ; \mathrm{Na} 2 \mathrm{SeO} 3,0.02 ; \mathrm{CuSO} 4 \cdot 5 \mathrm{H} 2 \mathrm{O}, 0.01 ; \mathrm{Ca}(\mathrm{IO} 3) 2 \cdot 6 \mathrm{H} 2 \mathrm{O}, 0.06$; zeolite, 8.485. ${ }^{\mathrm{d}}$ Others $\left(\mathrm{g} \mathrm{kg}^{-1}\right.$ diet): $\mathrm{Ca}\left(\mathrm{H}_{2} \mathrm{PO}_{4}\right)_{2}, 10.00$; soy lecithin, 20.00; attractant, 10.00; choline chloride, 3.00; sodium alginate, 5.00; Yttrium oxide, 1.00; calcium propionic acid, 0.50; taurine, 10.00; ethoxyquin, 0.50 .

remaining three fish were taken for analyses of digestive and immune-related enzyme activities. For microbiome analysis, the entire intestinal contents of another six fish per tank were aseptically taken and combined into one sample; thus, three samples per treatment were obtained. All the samples of plasma, intestinal tissues, and intestinal contents for enzyme activity examination and microbiome analysis were instantly frozen in liquid nitrogen and stored at $-80^{\circ} \mathrm{C}$.

\subsection{Analytical Methods}

2.6.1. Chemical Composition. Compositions of the ingredient and diet samples were analyzed using the standard method of AOAC (Association of Official Analytical Chemists) [25]. Ash was examined by muffle furnace at $550^{\circ} \mathrm{C}$ for $20 \mathrm{~h}$; crude protein was determined using the Kjeldahl method by multiplying the nitrogen content by 6.25 ; dry matter was analyzed by drying the samples to constant weight at $105^{\circ} \mathrm{C}$; crude lipid was measured by petroleum ether extraction with Soxhlet method. The contents of four essential amino acids (methionine, lysine, leucine, and arginine) in SM and LASM were determined as described by $\mathrm{Li}$ et al. [10]. Briefly, the samples were hydrolyzed with $6 \mathrm{~N} \mathrm{HCl}$ at $110^{\circ} \mathrm{C}$ for $22 \mathrm{~h}$ and then diluted to $5 \mathrm{~mL}$ with ultrapure water. The solvent solution was evaporated under nitrogen gas and then added $0.02 \mathrm{~N} \mathrm{HCl}$. The hydrolyzate was filtered through a $0.22 \mu \mathrm{m}$ nylon syringe filter and then analyzed by the L-8900 amino acid analyzer (Hitachi, Japan).

2.6.2. Lactic Acid and ANF Content Detection. Lactic acid content was determined using reverse-phase highperformance liquid chromatographic (RP-HPLC) method with the Cosmosil C18-MS-II column after ultrasonic extraction and filtration [26]. The main ANFs such as trypsin inhibitors (TI), glycinin, and $\beta$-conglycinin in SM and LASM were also measured. TI activity was determined with benzoyl-DL-argininep-nitroanilide (BAPA) method [27]. Briefly, TI was extracted in $0.01 \mathrm{~N} \mathrm{NaOH}$ and centrifugated at $10000 \mathrm{~g}$ for $10 \mathrm{~min}$. Then, the supernatant was blended with $0.05 \mathrm{~N}$ Tris- $\mathrm{HCl}$ and trypsin solution plus BAPA solution. Acetic acid $(30 \%, v / v)$ was added to finish the reaction after incubated at $37^{\circ} \mathrm{C}$ for $45 \mathrm{~min}$, and the absorbance was determined at $410 \mathrm{~nm}$. The contents of glycinin and $\beta$-conglycinin were quantified by the competitive ELISA method using kits from Longkefangzhou Bio-Engineering Technology Co. Ltd. (Beijing, China). The contents of the ANFs were presented as mg per $\mathrm{g}$ sample.

2.6.3. Enzyme Activity Assay. Intestinal tissues were mixed with ice-cold normal saline $(1: 9, v / v)$, adequately homogenized, then centrifuged at $2500 \mathrm{rpm}$ for $15 \mathrm{~min}$. The activities of several digestive enzymes (trypsin, lipase, and diastase) and immune-related enzymes (alkaline phosphatase (AKP) and acid phosphatase (ACP)) in the supernatants were measured with enzymatic colorimetric methods using kits from the Nanjing Jiancheng Bioengineering Company. Also, the activity of lysozyme (LZM) in plasma was measured with kits from the Nanjing Jiancheng Bioengineering Company. The reference numbers of the kits used for trypsin, lipase, diastase, AKP, ACP, and LZM were A080-2-2, A054-1-1, C016-1-1, A059-1-1, A060-1-1, and A050-1-1. The enzyme activity was determined in strict accordance with the kit instructions.

2.6.4. Gut Micromorphology. The histology analysis was performed following the description by the previous study [10]. The fixed specimens of distal intestine were dehydrated in gradient alcohol and embedded in paraffin wax, and 5micron-thick tissues were cut, installed onto glass slides, and then stained by hematoxylin and eosin (H\&E). A light microscope (Olympus, DP72) equipped with a camera and CellSens Standard Software was used for the image acquisition and the determination of villus height $(\mathrm{VH})$ and lamina propria width (LPW). Distal intestine samples from six fish per treatment were selected for the histology analysis, and three sections per sample were made, and then, 4-5 welloriented villus from each section were randomly selected for the determination of VH and LPW. After two-time average calculations, 6 data per treatment were finally obtained for subsequent statistical analysis.

2.6.5. High-Throughput Sequencing and Bioinformatic Analysis of Intestinal Microbiota. Total genomic DNA from intestinal content samples $(\sim 50 \mathrm{mg})$ was extracted with 
CTAB method. The 16S V4 hypervariable regions of highquality DNA were amplified using specific primer pair 515F (5'-GTGCCAGCMGCCGCGG-3 $\left.{ }^{\prime}\right) / 806 \mathrm{R}$ (5'-GGAC TACHVGGGTWTCTAAT- $3^{\prime}$ ) with the barcode. The amplification program was conducted by Phusion ${ }^{\circledR}$ HighFidelity PCR Master Mix (New England Biolabs). Thermal cycling consisted of initial denaturation at $98^{\circ} \mathrm{C}$ for $1 \mathrm{~min}$, followed by 30 cycles of denaturation at $98^{\circ} \mathrm{C}$ for $10 \mathrm{~s}$, annealing at $50^{\circ} \mathrm{C}$ for $30 \mathrm{~s}$, and elongation at $72^{\circ} \mathrm{C}$ for $30 \mathrm{~s}$. Pooled PCR products were purified using Qiagen Gel Extraction Kit (Qiagen, Germany), and sequencing libraries were constructed using TruSeq ${ }^{\circledR}$ DNA PCR-Free Sample Preparation Kit (Illumina, USA) with the addition of index codes. Lastly, the library was sequenced on an Illumina NovaSeq platform, and $250 \mathrm{bp}$ paired-end reads were generated.

The barcode and primer sequence of paired-end reads were removed, then merged using FLASH (v1.2.7) [28]. High-quality clean tags were acquired by quality filtering based on the QIIME (v1.9.1) [29]. The chimera sequences were determined in reference to the Silva database [30] using UCHIME algorithm [31] and then removed from the tags (Haas et al., 2011). Uparse software (v7.0.1001) [32] was used to measure the tags, and sequences with $\geq 97 \%$ similarity were distributed to the same OTUs. Representative sequence of each OTU was screened for further annotation of taxonomic information according to the Silva Database (Version 132) [30] with Mothur algorithm. The MUSCLE software (v3.8.31) [33] was applied to study the phylogenetic relationship construction, and the abundance information of OTUs was normalized with a standard of sequence number corresponding to the sample with the least sequences. Betadiversity analyses, including principal coordinate analysis (PCoA), nonmetric multidimensional scaling (NMDS) analysis, and unweighted pair-group method with arithmetic mean (UPGMA) analysis based on weighted unifrac distances, were included to compare the microbiome structure in different samples. NMDS was displayed by vegan package and PCoA by WGCNA package, stats packages, and ggplot2 package in $\mathrm{R}$ software (v2.15.3). For the environmental factor correlation analysis, the corr. test function of psych package in R software (v2.15.3) was used to calculate Spearman correlation values of species and environmental factors and test the significance. Then, pheatmap function in pheatmap package was used for visualization.

2.6.6. Calculations and Statistical Analysis. The following variables were calculated:

$$
\begin{gathered}
\text { Survival rate }(\mathrm{SR}, \%)=100 \times \frac{\text { final fish number }}{\text { initial fish number }}, \\
\text { Weight gain rate }(\mathrm{WGR}, \%)=\frac{(\text { final body weight }- \text { initial body weight })}{\text { initial body weight }} \times 100 \%,
\end{gathered}
$$

Specific growth rate $($ SGR, \%/d $)=\frac{(\text { Ln final body weight }- \text { Ln initial body weight }) \times 100}{\text { days }}$,
TABLE 2: The nutritional profile of SM and LASM.

\begin{tabular}{lcc}
\hline Nutritional parameters $\left(\mathrm{mgg}^{-1}\right)$ & SM & LASM \\
\hline Crude protein & $510.65 \pm 0.60$ & $535.80 \pm 5.67^{*}$ \\
Crude lipid & $30.57 \pm 0.45$ & $33.67 \pm 0.90^{*}$ \\
Methionine & $4.50 \pm 0.12$ & $4.43 \pm 0.20$ \\
Lysine & $27.70 \pm 0.42$ & $29.53 \pm 0.30^{*}$ \\
Leucine & $33.13 \pm 0.55$ & $36.87 \pm 0.61^{*}$ \\
Arginine & $30.17 \pm 0.54$ & $33.27 \pm 0.73^{*}$ \\
Lactic acid & $0.00 \pm 0.00$ & $44.61 \pm 1.19^{* * *}$ \\
Trypsin inhibitors & $2.82 \pm 0.07$ & $0.39 \pm 0.04^{* * *}$ \\
Glycinin & $171.91 \pm 5.93$ & $43.52 \pm 0.72^{* * *}$ \\
$\beta$-Conglycinin & $127.70 \pm 6.12$ & $61.10 \pm 1.20^{* * *}$ \\
\hline
\end{tabular}

Note: Values are displayed as mean \pm standard error $(n=3) .{ }^{*} p<0.05$; ${ }^{* *} p<0.01 ;{ }^{* * *} p<0.001$. SM: soybean meal; LASM: L. acidophilusfermented soybean meal.

TABLE 3: Growth performance and feed utilization of turbot fed experimental diets.

\begin{tabular}{lccc}
\hline Parameters & CNT group & SM group & LASM group \\
\hline SR $(\%)$ & $98.89 \pm 1.11$ & $97.78 \pm 1.11$ & $97.78 \pm 1.11$ \\
WGR $(\%)$ & $257.28 \pm 7.51^{\mathrm{a}}$ & $190.45 \pm 7.24^{\mathrm{b}}$ & $236.54 \pm 4.95^{\mathrm{a}}$ \\
SGR $\left(\% \mathrm{~d}^{-1}\right)$ & $2.40 \pm 0.04^{\mathrm{a}}$ & $2.01 \pm 0.05^{\mathrm{b}}$ & $2.29 \pm 0.03^{\mathrm{a}}$ \\
FI $\left(\% \mathrm{~d}^{-1}\right)$ & $1.47 \pm 0.01^{\mathrm{a}}$ & $1.48 \pm 0.01^{\mathrm{a}}$ & $1.55 \pm 0.01^{\mathrm{b}}$ \\
FER $\left(\mathrm{g} \mathrm{g}^{-1}\right)$ & $1.45 \pm 0.02^{\mathrm{a}}$ & $1.24 \pm 0.02^{\mathrm{b}}$ & $1.32 \pm 0.02^{\mathrm{b}}$ \\
PER $\left(\mathrm{g} \mathrm{g}^{-1}\right)$ & $2.41 \pm 0.03^{\mathrm{a}}$ & $2.07 \pm 0.03^{\mathrm{b}}$ & $2.19 \pm 0.03^{\mathrm{b}}$ \\
\hline
\end{tabular}

Note: Values show mean \pm standard error, $n=3$; values in the same column with different superscripted small letters $(\mathrm{a}, \mathrm{b})$ represent statistical differences based on Tukey's test $(p<0.05$, one-way ANOVA). SR: survival rate; WGR: weight gain rate; SGR: specific growth rate; FI: feed intake; FER: feed efficiency ratio; PER: protein efficiency ratio.

Daily feed intake $(\mathrm{DFI}, \% / \mathrm{d})=\frac{100 \times \text { dry feed intake }(\mathrm{g}) /[(\text { final body weight }+ \text { initial body weight }) / 2]}{\text { days }}$,

Feed efficiency ratio $($ FER $)=\frac{\text { wet total weight gain }(\mathrm{g})}{\text { dry total feed intake }(\mathrm{g})}$,

Protein efficiency ratio $(\mathrm{PER})=\frac{\text { wet weight gain }(\mathrm{g})}{\text { protein ingested }(\mathrm{g})}$.

SPSS 22.0 software (SPSS Inc., Chicago, IL, USA) was applied to perform statistical analysis. Comparison of data of nutritional profile in SM and LASM was performed by independent samples $t$ tests. All the other data were subjected to one-way analysis of variance (ANOVA) followed by Tukey's test. All the data were examined for homogeneity of variances prior to the statistical analysis. Differences were regarded as significant at $p<0.05$. The final data were expressed as means \pm standard error. 


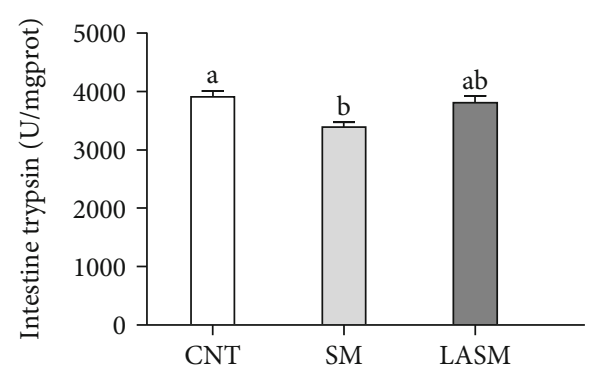

(a)

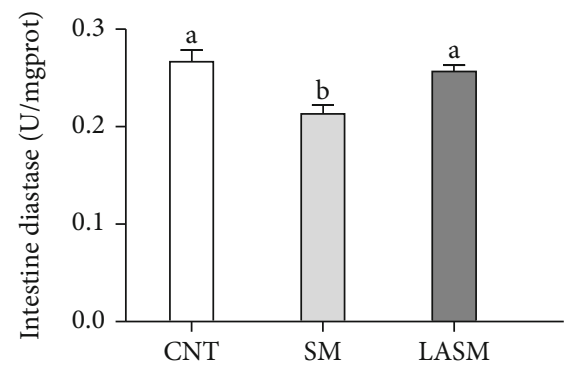

(c)

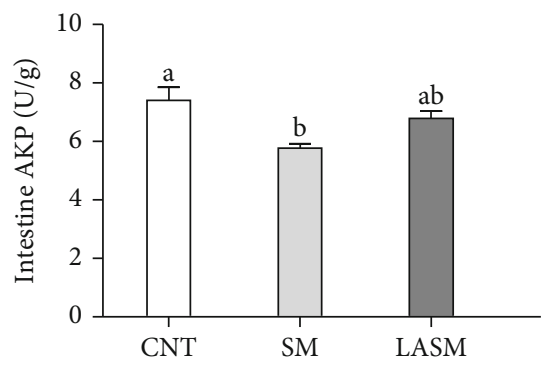

(e)

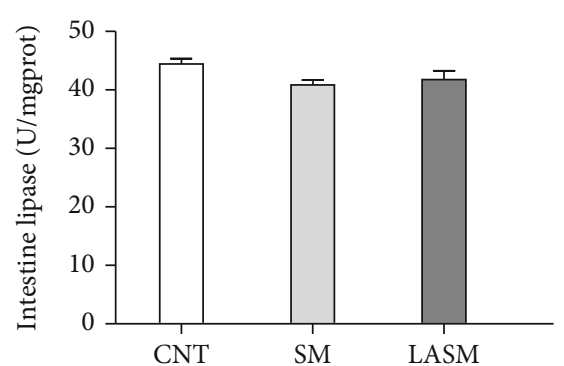

(b)

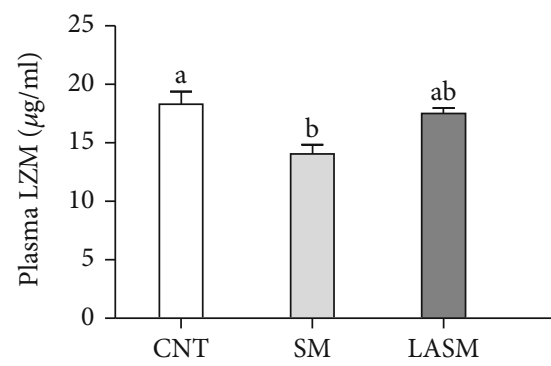

(d)

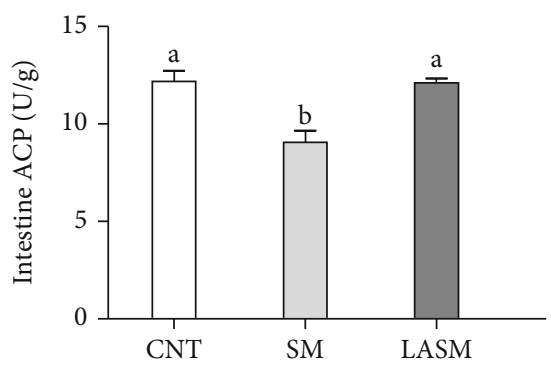

(f)

Figure 1: Digestive and immune enzymes activities in turbot. (a) Intestinal trypsin; (b) intestinal lipase; (c) intestinal diastase; (d) plasma lysozyme (LZM); (e) intestinal alkaline phosphatase (AKP); (f) intestinal acid phosphatase (ACP). Values are displayed as means \pm standard error $(n=3)$. Different letters $(a, b)$ above the bars represent statistical differences based on Tukey's test $(p<0.05$, one-way ANOVA).

\section{Results}

3.1. Nutritional Profile of SM and LASM. The nutritional profile of SM and LASM were displayed in Table 2. L. acidophilus fermentation significantly increased the levels of crude protein $(+4.93 \%)$ and crude lipid $(+10.13 \%)$. An increase was also observed in lysine $(+6.23 \%)$, leucine $(+11.36 \%)$, and arginine $(+10.22 \%)$, while no significant difference was found in methionine. Tiny amount of lactic acid $\left(0.0014 \mathrm{mgg}^{-1}\right)$ in SM was detected, while significantly increased lactic acid content $\left(44.61 \mathrm{mg} \mathrm{g}^{-1}\right)$ was observed in LASM. Furthermore, L. acidophilus fermentation significantly decreased the level of ANFs in SM, such as trypsin inhibitors $(-86.04 \%)$, glycinin $(-74.68 \%)$, and $\beta$-conglycinin $(-52.16 \%)$.

3.2. Growth Performance and Feed Utilization. After the feeding trial, no significant difference was found in SR among groups $(p>0.05)$. Fish WGR and SGR decreased significantly in the SM group $(p<0.05)$, while fish in the LASM group showed comparable growth performance to those in the CNT group $(p>0.05)$. Fish fed with the LASM diet dis- played the highest DFI among the dietary groups $(p<0.05)$; however, FER and PER were remarkably decreased in SM and LASM groups compared with the CNT group $(p<0.05)$ (Table 3).

3.3. Digestive and Immune-Related Enzyme Activities. The activities of trypsin and diastase in the SM group were remarkably lower than those in the control group $(p<0.05)$; however, no significant reduction was observed in the LASM group ( $p>0.05$, Figures $1(\mathrm{a})$ and $1(\mathrm{c}))$. The activity of intestinal lipase showed no significant differences among groups (Figure 1(b)). For the immunerelated enzyme activities, the $\mathrm{CNT}$ group had the highest activities of LZM, AKP, and ACP, followed by the LASM group, and the lowest in the SM group $(p<0.05$, Figures 1(d)-1(f)).

3.4. Intestinal Morphology. Intestinal micromorphological analysis was performed to visually evaluate the influences of different diets on the intestinal health of turbot. As shown in Figures 2(a)-2(c), the widened lamina propria and inflammatory cell infiltration were observed in fish fed the 


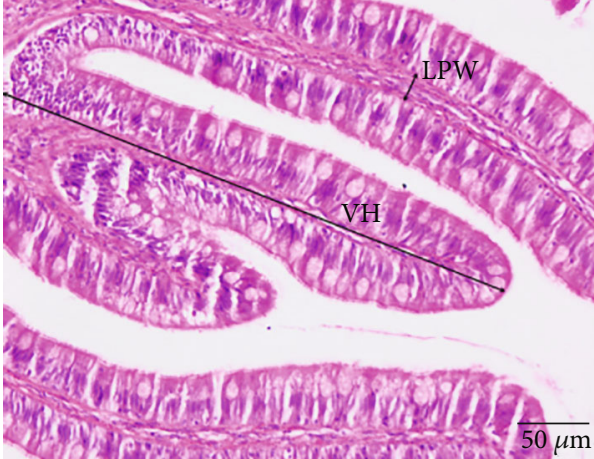

(a)

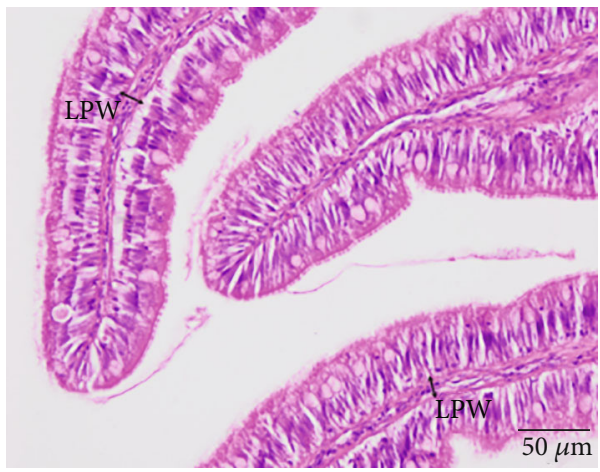

(c)

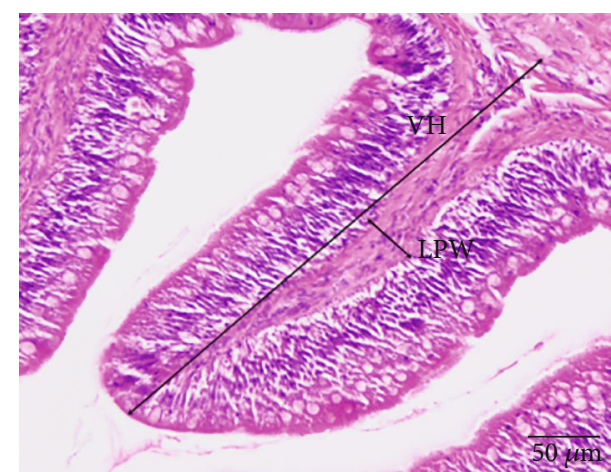

(b)

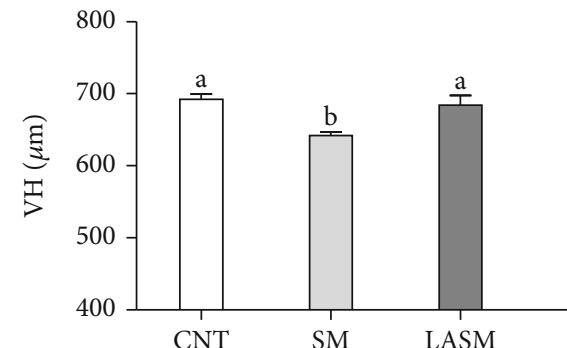

(d)

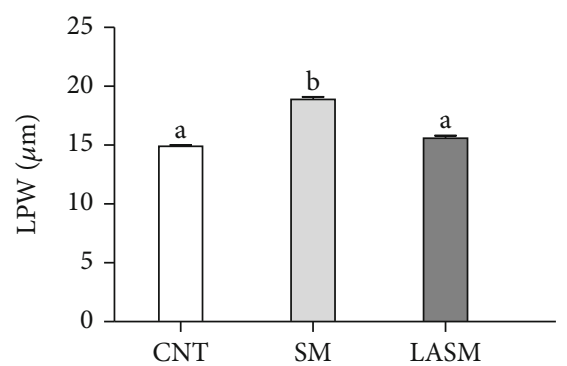

(e)

FIgURE 2: Intestinal morphology analysis in turbot. (a) Typical image of the CNT group; (b) typical image of the SM group; (c) typical image of the LASM group; (d) villus height (VH) of turbot intestine; (e) lamina propria width (LPW) of turbot intestine. Values are displayed as means \pm standard error $(n=6)$. Different letters $(\mathrm{a}, \mathrm{b})$ above the bars represent statistical differences based on Tukey's test $(p<0.05$, one-way ANOVA).

SM diet. Further statistical analysis showed that VH and LPW were significantly reduced or increased, respectively, in the SM group compared to the CNT group $(p<0.05)$. However, significant improvements of intestinal microstructure were found in the LASM group, showing similar levels of VH and LPW to the CNT group ( $p>0.05$, Figures $2(\mathrm{~d})$ and $2(\mathrm{e}))$.

3.5. Intestinal Microbiota. The influences of dietary SM or LASM on the intestinal microbiota of turbot were investigated on an Illumina NovaSeq platform using high throughput sequencing technology. Rarefaction analysis was displayed in Figure 3(a), and adequate sequencing depth was achieved for all samples. Furthermore, 5260 OTUs were obtained via annotation: 1242 OTUs were shared by the three groups, and 1054, 393, and 708 OTUs were only detected in the CNT, SM, and LASM groups, respectively (Figure $3(\mathrm{~b})$ ). The $\beta$-diversity analysis of PCoA (Figure 4(a)), NMDS (Figure 4(b)), and UPGMA (Figure 4(c)) based on weighted UniFrac distances suggested that the LASM cluster was more similar to the CNT cluster and obviously separated from the SM cluster. The findings revealed that the overall microbiota profile in LASM-fed group, rather than SM-fed group, was more consistent with the CNT group.

As shown in Figures 5(a) and 5(b), Proteobacteria, Firmicutes, and Bacteroidetes were identified as the top three predominant bacterial phyla in fish intestine from all groups. Proteobacteria and Bacteroidetes were much lower in the CNT group than in the SM group, while Firmicutes showed an opposite tendency $(p<0.05)$ (Figure $5(\mathrm{~b}))$. The relative abundances of the top three bacterial phyla in the LASM 


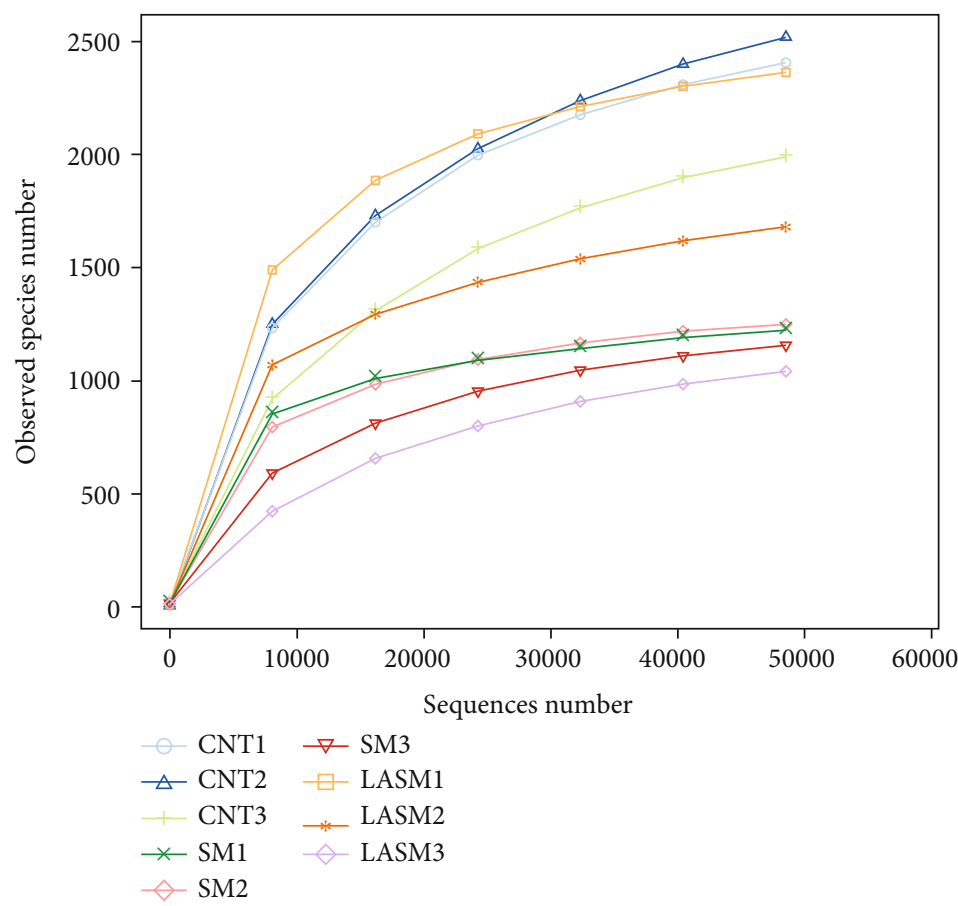

(a)

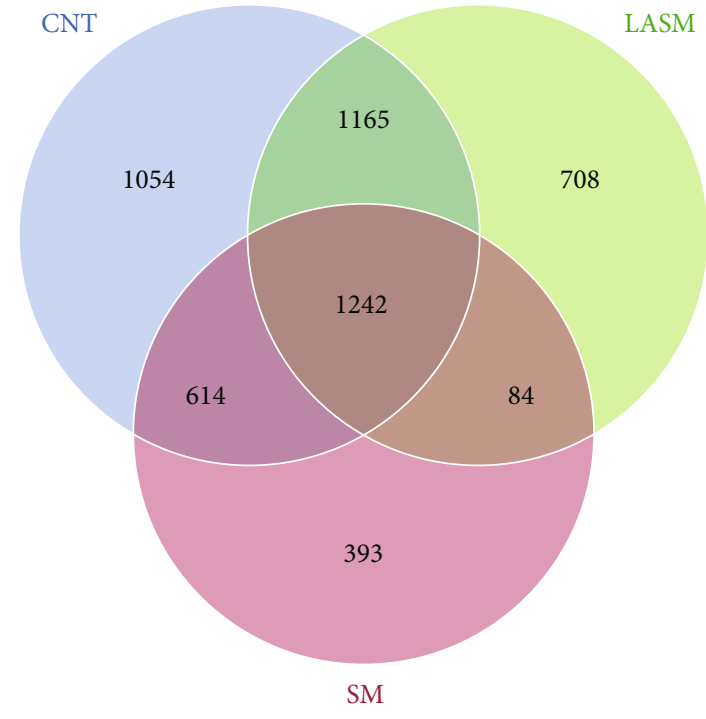

(b)

Figure 3: Rarefied curves and Venn diagram. (a) Rarefaction curves of observed species number for all the intestinal content samples. (b) Venn diagram of unique and shared OTUs. CNT1, CNT2, and CNT3 are three replicates of the CNT group; SM1, SM2, and SM3 are three replicates of the SM-fed group; LASM1, LASM2, and LASM3 are three replicates of the LASM-fed group.

group remained similar to those in the CNT group (Figure 5(b)). At genus level, Cobetia, Pseudomonas, Lactobacillus, Leuconostoc, Streptococcus, Lactococcus, Psychrobacter, Prevotella, Blautia, and Ruminococcus composed the top ten dominant genera in turbot intestine (Figure 5(c)). As shown in Figure 5(d), Spearman's correlation analysis displayed that Proteobacteria was negatively associated with the diastase activity $(p<0.05)$, while Firmicutes, unidentified_Bacteria, Actinobacteria, and Cyanobacteria were positively associated with the diastase activity $(p<0.05)$. Furthermore, Cyanobacteria, and Crenarchaeota were positively associated with the lipase activity $(p<0.05)$, and unidentified_Bacteria was positively associated with the LZM activity $(p<0.05)$. Interestingly, the abundances of Firmicutes, Actinobacteria, and Cyanobacteria were highest in the CNT group, followed by the LASM group, and was lowest in the SM group; however, Proteobacteria showed an opposite tendency $(p<0.05)$. These results revealed that dietary LASM could exhibit beneficial influence on the intestinal microbiota, which further contributed to the improvement of the digestive function in turbot.

\section{Discussion}

Unbalanced essential amino acid (EAA) composition, poor palatability, and the presence of ANFs greatly restrict the application of SM in aquafeed $[2,34]$. To evaluate the effects of fermentation, the conventional nutritional composition (crude protein and crude lipid) and the content of four
EAAs, flavor substance, and major ANFs in SM and LASM were specifically determined. A moderate increase was observed in the crude protein level $(+4.93 \%)$ after fermentation, which was superior to previous report showed that the crude protein level in SM could be elevated by $1.75 \%$ after $L$. acidophilus fermentation [13]. Furthermore, the levels of lysine, arginine, and leucine, which are crucial to growth in fish, were increased by fermentation. Similar results were obtained in our previous study of Aspergillus awamori fermentation, which improved the amino acid profile of SM [10]. Lactic acid is an important flavor substance that can enhance feed palatability and digestibility [35]. Meanwhile, lactic acid is also an important antibacterial compound, which can reduce $\mathrm{pH}$ and redox potential in the intestine, forming an acidic environment, inhibiting acid-intolerant pathogenic bacteria, and thereby, regulating the balance of gut microbiota [36]. This study showed that almost no lactic acid was detected in raw SM, but LASM had a significantly higher lactic acid content $\left(44.61 \mathrm{mgg}^{-1}\right)$, which suggested that the probiotic properties of LASM were significantly enhanced. Moreover, L. acidophilus fermentation reduced the contents of ANFs including trypsin inhibitors $(-86.04 \%)$, glycinin $(-74.68 \%)$, and $\beta$-conglycinin $(-52.16 \%)$. The ability of $L$. acidophilus to degrade the selected ANFs in SM is comparable to that of $L$. plantarum P8, which could reduce the contents of trypsin inhibitors $(-87 \%)$, glycinin $(-78 \%)$, and $\beta$-conglycinin (-55\%) through fermentation [14]. The production of various extracellular enzymes during fermentation generally accounts for the 


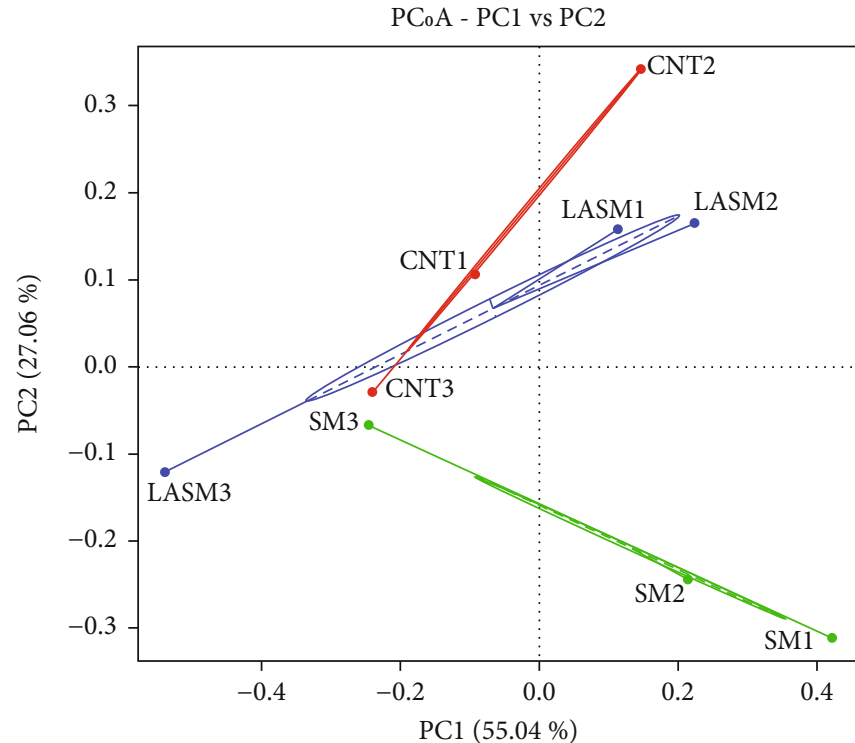

- CNT

- SM

- LASM

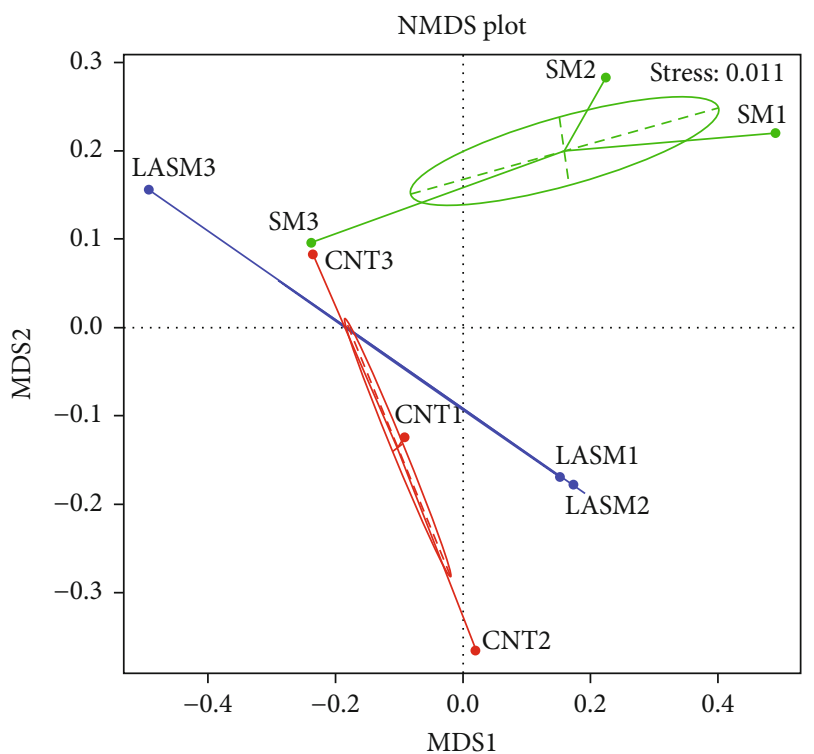

- CNT

- SM

- LASM

(a)

(b)
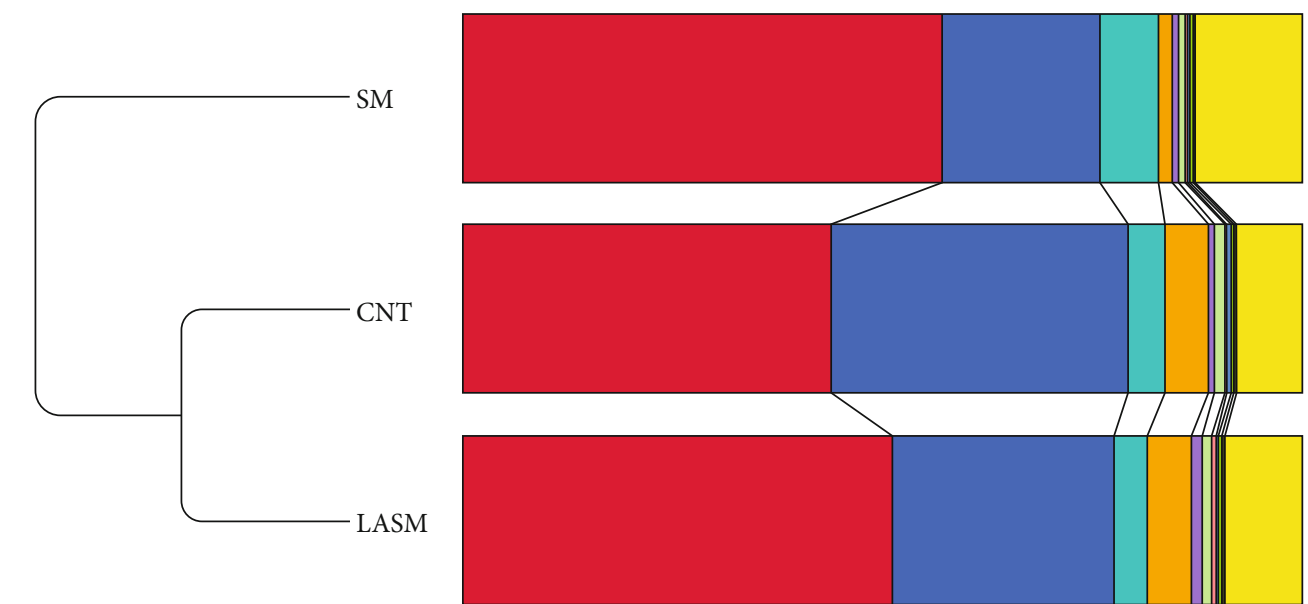

Weighted_unifrac distance

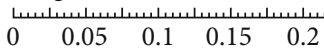

0

0.25

0.5

0.75

Relative abundance in phylum level

$\begin{array}{ll}\text { Proteobacteria } & \text { Chloroflexi } \\ \text { Firmicutes } & \text { Cyanobacteria } \\ \text { Bacteroidota } & \text { Desulfobacterota } \\ \text { Unidentified_bacteria } & \text { Verrucomicrobiota } \\ \text { Acidobacteriota } & \text { Others } \\ \text { Actinobacteriota } & \end{array}$

(c)

FIgURE 4: Comparison of intestinal microbiome profile in turbot fed different diets. (a) Principal coordinates analysis (PCoA) based on weighted UniFrac metrics. (b) Nonmetric multidimensional scaling (NMDS) analysis based on weighted UniFrac metrics. (c) Unweighted pair-group method with arithmetic mean (UPGMA) analysis based on weighted UniFrac metrics. CNT1, CNT2, and CNT3 are three replicates of the CNT group; SM1, SM2, and SM3 are three replicates of the SM-fed group; LASM1, LASM2, and LASM3 are three replicates of the LASM-fed group. 

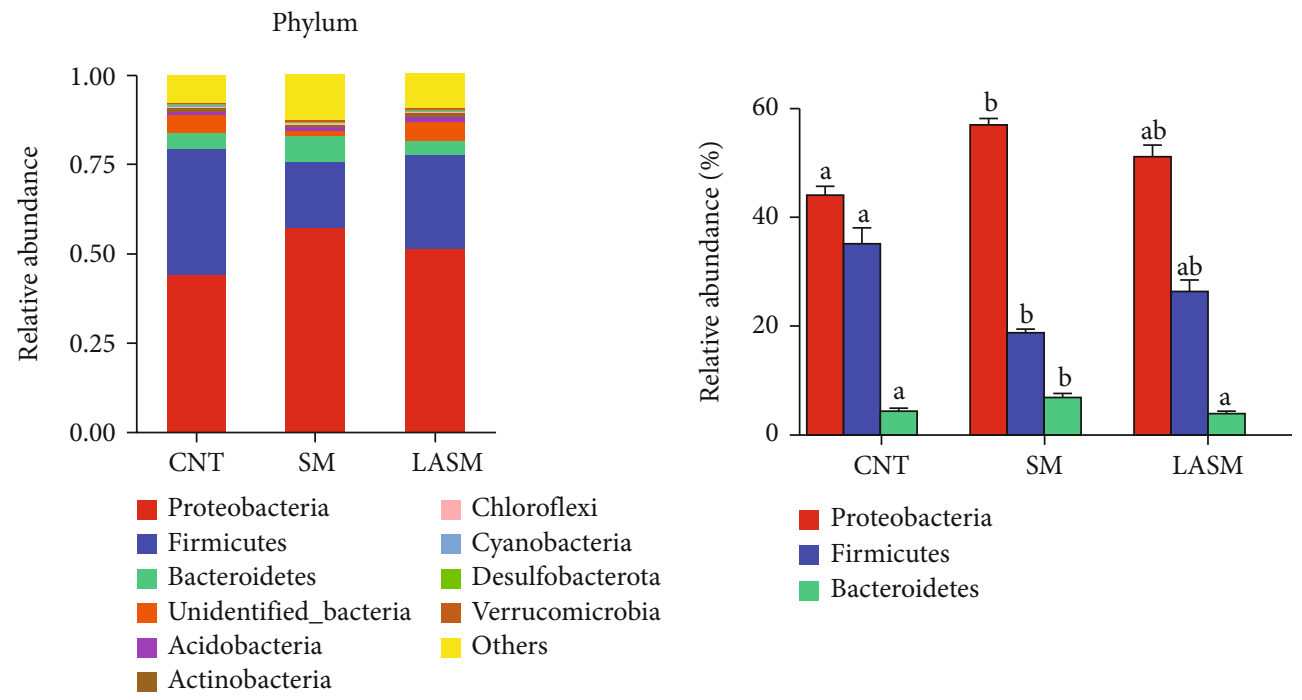

(a)

(b)
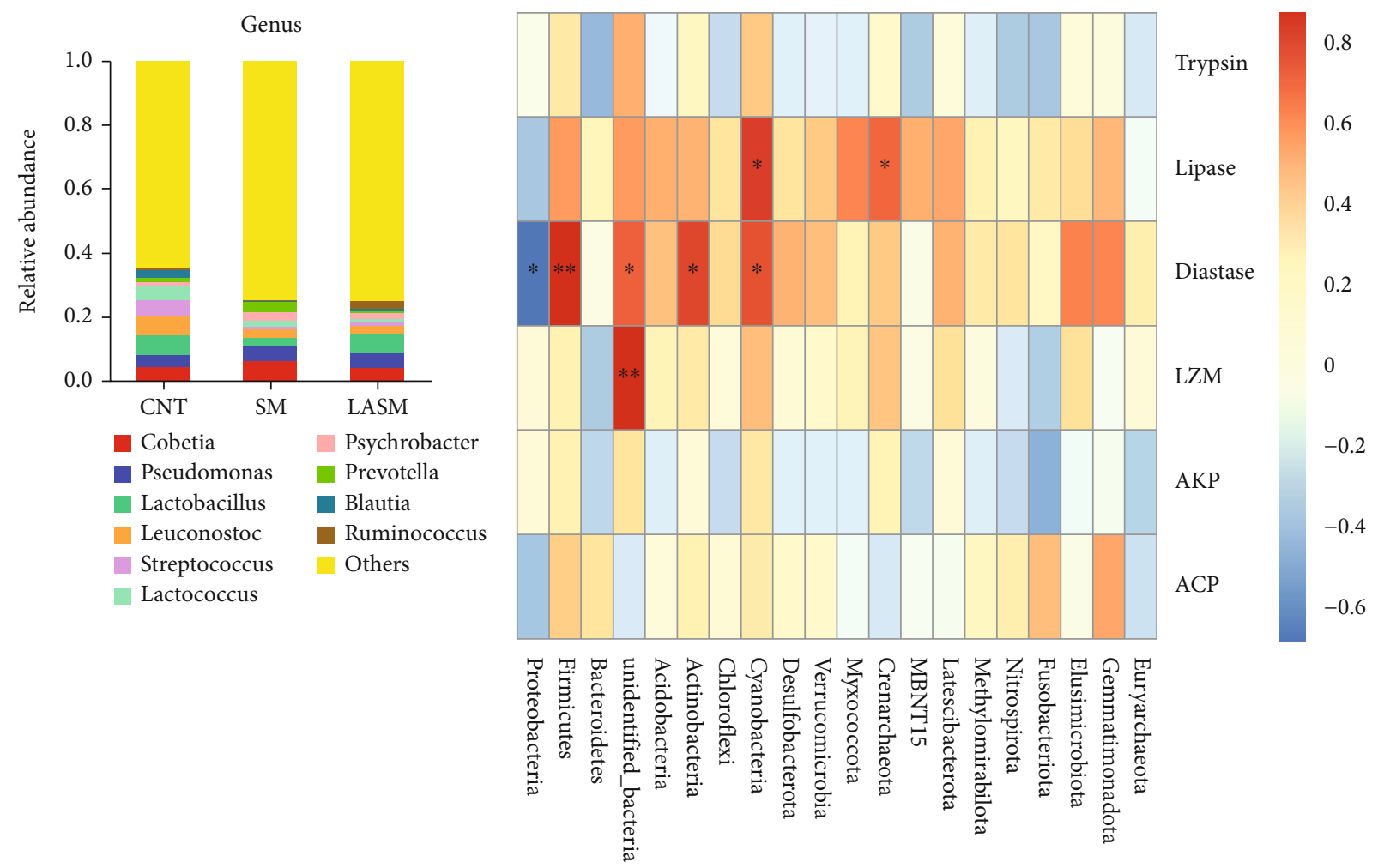

(c)

(d)

FIGURE 5: Specific microbiota composition and environmental factor correlation analysis in turbot fed different diets. (a) Relative abundance of bacterial phyla in different treatments. (b) Top three dominant bacterial phyla in different treatments. (c) Relative abundance of bacterial genera in different treatments. (d) Correlation analysis of the microbiota with the digestive and immune-related enzyme activities of turbot based on Spearman correlations. ${ }^{*} p<0.05 ;{ }^{* *} p<0.01$.

degradation of ANFs [37]. Taken together, the nutrition profile of SM was improved via L. acidophilus fermentation, which prompted us to perform further feeding trials.

Our previous studies provided abundant evidence that substituting $45 \%$ of fishmeal protein with SM induced growth impairment and intestine dysfunction in turbot $[10,21]$. Therefore, LASM was used to replace the same level (45\%) of fishmeal protein, expecting that L. acidophilus fer- mentation could remove or alleviate the SM-induced adverse effects in turbot. As assumed, turbot fed the LASM diet exhibited better growth performance than those fed the SM diet. Beneficial effects of Lactobacillus spp.-fermented SM on the growth performance of carnivorous fish could be also observed in Atlantic salmon [38], turbot [14], and grouper [39]. As for the feed utilization performance, the highest DFI was found in the LASM group among the three dietary 
groups, and FER and PER in the LASM group were slightly higher than those in the SM group. This may be due to the increase of lactic acid and the decrease of ANFs in LASM through fermentation.

The activities of intestinal digestive enzymes (protease, lipase, and amylase) were measured the better to understand the influences of dietary SM or LASM on the digestive function of turbot. The activities of trypsin and diastase displayed a depression in the SM group, while the LASM group remained similar to those in the CNT group. There is definite evidence that trypsin inhibitor in SM (SBTI) can suppress pancreatic protease activity, thus affecting the digestive process [40]. However, an earlier study by Olli et al. [41] reported that the Atlantic salmon could exhibit compensatory effect for SBTI in vivo, maintaining protein digestibility if SBTI is included in the diet below a given threshold. In the present study, the reduction of intestinal trypsin activity in the SM group indicated that the SBTI content in the SM-based diet might exceed the threshold for turbot tolerance. The secretion of intestinal digestive enzymes could be regulated by dietary components [42]. The intestinal microbiota could also contribute various enzymes for the host [43]. The shifted microbiota and decrease of trypsin inhibitor through fermentation could partially contribute to the higher digestive enzyme activity in LASM-fed group. Furthermore, results demonstrated that the CNT group had the highest activities of LZM, AKP, and ACP, followed by the LASM group, and the lowest in the SM group. According to the previous study, L. acidophilus can stimulate the immune system and actively regulate the immune function of the host [16]. In this study, low-temperature drying was used for the preparation of LASM, and the remaining active or even heat-killed $L$. acidophilus may stimulate the immune system and increase the immune-related enzyme activities in turbot fed with the LASM-based diet.

Pathological changes with widened lamina propria and inflammatory cell infiltration were observed in fish fed SM diet. Statistical analysis showed that VH and LPW were significantly reduced or increased, respectively, in the SM group which was in line with the findings by Zhang et al. [44] and Li et al. [4]; however, a significant improvement was found in the LASM group. The improvement of intestinal histology through dietary fermented SM has been extensively reported in various fish species such as large yellow croaker (Larimichthys crocea) [45], largemouth bass (Micropterus salmoides) [4], and Florida pompano (Trachinotus carolinus) [46]. ANFs including antigen protein, saponin, and lectin in SM can destroy the intestinal structure of fish [47-49]. In this study, the glycinin and $\beta$-conglycinin were dramatically eliminated via fermentation, which may account for the improvement of intestinal health in turbot fed the LASM diet.

Recently, research on the response mechanism of fish intestinal microbiota to dietary components has attracted much attention [50]. Different from our previous study [10] which only focused on the effects of dietary raw or fermented SM on intestinal histology and inflammation status of fish, the better to explore the underlying mechanism behind the different performances of intestinal function, the intestinal microbiota of turbot fed with different experimental diets were investigated. Both PCoA and NMDS analysis showed clearly separated clusters, revealing that the intestinal microbiota exhibited different response patterns to different diets. Interestingly, beta-diversity analysis of PCoA, NMDS, and UPGMA suggested that the clusters and microbiota profile in CNT and LASM groups were relatively coherent, while those in the SM group were separated. Similar findings have also been observed in previous studies $[21,24]$. For the specific microbiota composition, dietary SM remarkably decreased Firmicutes and increased Proteobacteria and Bacteroidetes compared to the CNT group. Nevertheless, the relative abundances of the top three bacterial phyla in the LASM group remained similar to those in the CNT group, which matched the results of the aforementioned beta-diversity analysis. Bacteroides are typified by their strong ability to degrade carbohydrates [51]. The relatively higher amount of carbohydrates in SM may be responsible for the enrichment of Bacteroides, while L. acidophilus fermentation might reduce the carbohydrate content in LASM. The excessive enrichment of Proteobacteria is generally considered a sign of dysbacteriosis [52, 53].

Complex host-microbiota interactions occur throughout the digestive process $[54,55]$; the study of which can also be helpful for better understanding the mechanism behind the changes of intestinal function. Previous studies regarding the evaluation of fermented SM in aquafeed generally ignored the correlation between the intestinal microbiota changes and the intestinal function in fish. In the present study, environmental factors were subjected to Spearman correlation analysis showing that Proteobacteria was negatively associated with the diastase activity, while Firmicutes, Actinobacteria, and Cyanobacteria were positively associated with the diastase activity. Moreover, Cyanobacteria and Crenarchaeota were positively associated with the lipase activity. This finding combined with the results of aforementioned microbiota composition revealed that the shifted microbiota induced by different diets could contribute to the regulation of digestive function in turbot.

\section{Conclusion}

L. acidophilus fermentation can improve the quality of SM through improving the EAA profile, increasing the lactic acid content, and decreasing the level of ANFs. The assessment by a feeding trial showed that turbot fed the LASM diet exhibited better performance in growth, feed utilization, intestinal digestive and immune-related enzyme activities, and morphology than those fed the SM diet. In particular, dietary LASM can positively regulate the intestinal microbiota, which further contributed to the improvement of the intestinal digestive function in turbot. This study indicates that $L$. acidophilus fermentation can improve the nutritional quality of SM and relieve SM-induced adverse effects on turbot. In the future, we intend to perform further study to evaluate the interplays between the L. acidophilus strain and the intestinal function (especially the intestinal immune function) of turbot. 


\section{Data Availability}

All data to support the findings of this study are included within the article.

\section{Conflicts of Interest}

The authors declare that they have no conflicts of interest.

\section{Acknowledgments}

This project was supported by the Natural Science Foundation of Shandong Province (grant nos. ZR2020MC053 and ZR202102180372). We thank professor Gen He (Ocean University of China) for the support in feeding trial and data analysis. We are also grateful to professor Xiuzhen Gao (Shandong University of Technology) for the help in laboratory instruments and equipment.

\section{References}

[1] K. Hua, J. M. Cobcroft, A. Cole et al., "The future of aquatic protein: implications for protein sources in aquaculture diets," One Earth, vol. 1, no. 3, pp. 316-329, 2019.

[2] D. M. Gatlin III, F. T. Barrows, P. Brown et al., "Expanding the utilization of sustainable plant products in aquafeeds: a review," Aquaculture Research, vol. 38, no. 6, pp. 551-579, 2007.

[3] G. Francis, H. P. S. Makkar, and K. Becker, "Antinutritional factors present in plant-derived alternate fish feed ingredients and their effects in fish," Aquaculture, vol. 199, no. 3-4, pp. 197-227, 2001.

[4] S. Li, G. Ding, F. Song, C. Sang, A. Wang, and N. Chen, "Comparison of dehulled, fermented and enzyme-treated soybean meal in diets for largemouth bass, Micropterus salmoides: effects on growth performance, feed utilization, immune response and intestinal morphology," Animal Feed Science and Technology, vol. 267, 2020.

[5] G. Baeverfjord and A. Krogdahl, "Development and regression of soybean meal induced enteritis in Atlantic salmon, Salmo salar L, distal intestine: a comparison with the intestines of fasted fish," Journal of Fish Diseases, vol. 19, no. 5, pp. 375$387,1996$.

[6] M. Coronado, C. J. Solis, P. P. Hernandez, and C. G. Feijoo, "Soybean meal-induced intestinal inflammation in zebrafish is T cell-dependent and has a Th17 cytokine profile," Frontiers in Immunology, vol. 10, p. 610, 2019.

[7] T. Vandeningh, A. Krogdahl, J. J. Olli, H. Hendriks, and J. Koninkx, "Effects of soybean-containing diets on the proximal and distal intestine in Atlantic salmon (Salmo salar): a morphological study," Aquaculture, vol. 94, no. 4, pp. 297305, 1991.

[8] H. C. Wei, P. Chen, X. F. Liang et al., "Plant protein diet suppressed immune function by inhibiting spiral valve intestinal mucosal barrier integrity, anti-oxidation, apoptosis, autophagy and proliferation responses in Amur sturgeon (Acipenser schrenckii)," Fish \& Shellfish Immunology, vol. 94, pp. 711722, 2019.

[9] M. D. Drew, T. L. Borgeson, and D. L. Thiessen, "A review of processing of feed ingredients to enhance diet digestibility in finfish," Animal Feed Science and Technology, vol. 138, no. 2, pp. 118-136, 2007.
[10] C. Li, B. Zhang, H. Zhou et al., "Beneficial influences of dietary Aspergillus awamori fermented soybean meal on oxidative homoeostasis and inflammatory response in turbot (Scophthalmus maximus L.)," Fish \& Shellfish Immunology, vol. 93, pp. 8-16, 2019.

[11] S.-H. Seo and S.-J. Cho, "Changes in allergenic and antinutritional protein profiles of soybean meal during solid-state fermentation with Bacillus subtilis," Lwt-Food Science and Technology, vol. 70, pp. 208-212, 2016.

[12] B. P. Singh, S. Vij, and S. Hati, "Functional significance of bioactive peptides derived from soybean," Peptides, vol. 54, pp. 171-179, 2014.

[13] C.-H. Chi and S.-J. Cho, "Improvement of bioactivity of soybean meal by solid-state fermentation with Bacillus amyloliquefaciens versus Lactobacillus spp. and Saccharomyces cerevisiae," Lwt-Food Science and Technology, vol. 68, pp. 619-625, 2016.

[14] L. Wang, H. Zhou, R. He, W. Xu, K. Mai, and G. He, "Effects of soybean meal fermentation by Lactobacillus plantarum P8 on growth, immune responses, and intestinal morphology in juvenile turbot (Scophthalmus maximus L.)," Aquaculture, vol. 464, pp. 87-94, 2016.

[15] M. Bull, S. Plummer, J. Marchesi, and E. Mahenthiralingam, "The life history of Lactobacillus acidophilus as a probiotic: a tale of revisionary taxonomy, misidentification and commercial success," FEMS Microbiology Letters, vol. 349, no. 2, pp. 77-87, 2013.

[16] Z. Abdo, J. LeCureux, A. LaVoy, B. Eklund, E. P. Ryan, and G. A. Dean, "Impact of oral probiotic Lactobacillus acidophilus vaccine strains on the immune response and gut microbiome of mice," PLoS One, vol. 14, no. 12, article e0225842, 2019.

[17] J. M. Remes Troche, E. Coss Adame, M. A. Valdovinos Diaz et al., "Lactobacillus acidophilus LB: a useful pharmabiotic for the treatment of digestive disorders," Therapeutic Advances in Gastroenterology, vol. 13, 2020.

[18] S. H. Hoseinifar, Z. Roosta, A. Hajimoradloo, and F. Vakili, "The effects of Lactobacillus acidophilus as feed supplement on skin mucosal immune parameters, intestinal microbiota, stress resistance and growth performance of black swordtail (Xiphophorus helleri)," Fish \& Shellfish Immunology, vol. 42, no. 2, pp. 533-538, 2015.

[19] M. Hosseini, H. K. Miandare, S. H. Hoseinifar, and P. Yarahmadi, "Dietary Lactobacillus acidophilus modulated skin mucus protein profile, immune and appetite genes expression in gold fish (Carassius auratus gibelio)," Fish \& Shellfish Immunology, vol. 59, pp. 149-154, 2016.

[20] M. S. Hassaan, A. M. I. El-Sayed, E. Y. Mohammady et al., "Eubiotic effect of a dietary potassium diformate (KDF) and probiotic (Lactobacillus acidophilus) on growth, hematobiochemical indices, antioxidant status and intestinal functional topography of cultured Nile tilapia Oreochromis niloticus fed diet free fishmeal," Aquaculture, vol. 533, 2021.

[21] C. Li, B. Zhang, X. Wang et al., "Improved utilization of soybean meal through fermentation with commensal Shewanella sp. MR-7 in turbot (Scophthalmus maximus L.)," Microbial Cell Factories, vol. 18, no. 1, pp. 214-214, 2019.

[22] Y. Liu, G. He, Q. Wang, K. Mai, W. Xu, and H. Zhou, "Hydroxyproline supplementation on the performances of high plant protein source based diets in turbot (Scophthalmus maximus L.)," Aquaculture, vol. 433, pp. 476-480, 2014. 
[23] N. Bai, M. Gu, X. Xu, B. Xu, and A. Krogdahl, "Protective effects of mannan oligosaccharides on turbot Scophthalmus maximus suffering from soy enteropathy," Aquaculture, vol. 476, pp. 141-151, 2017.

[24] G. Yu, Y. Liu, W. Ou et al., "The protective role of daidzein in intestinal health of turbot (Scophthalmus maximus L.) fed soybean meal-based diets," Scientific Reports, vol. 11, no. 1, 2021.

[25] "AOAC (Association of Official Analytical Chemists)," in Official Methods of Analysis, Association of Official Analytical Chemists, 18th edition, 2005.

[26] D. M. Bai, R. Ban, X. M. Zhao, and Z. D. Hu, "Determination of lactic acid in fermentation broth of Rhizopus oryzae by reversed-phase high performance liquid chromatography (RP-HPLC)," Se pu = Chinese journal of chromatography, vol. 18, no. 6, pp. 527-528, 2000, (in Chinese).

[27] C. Dai, H. Ma, R. He et al., "Improvement of nutritional value and bioactivity of soybean meal by solid-state fermentation with Bacillus subtilis," Lwt-Food Science and Technology, vol. 86, pp. 1-7, 2017.

[28] T. Magoc and S. L. Salzberg, "FLASH: fast length adjustment of short reads to improve genome assemblies," Bioinformatics, vol. 27, no. 21, pp. 2957-2963, 2011.

[29] J. G. Caporaso, J. Kuczynski, J. Stombaugh et al., "QIIME allows analysis of high-throughput community sequencing data," Nature Methods, vol. 7, no. 5, pp. 335-336, 2010.

[30] C. Quast, E. Pruesse, P. Yilmaz et al., "The SILVA ribosomal RNA gene database project: improved data processing and web-based tools," Nucleic Acids Research, vol. 41, no. D1, pp. D590-D596, 2013.

[31] R. C. Edgar, B. J. Haas, J. C. Clemente, C. Quince, and R. Knight, "UCHIME improves sensitivity and speed of chimera detection," Bioinformatics, vol. 27, no. 16, pp. 21942200, 2011.

[32] R. C. Edgar, "UPARSE: highly accurate OTU sequences from microbial amplicon reads," Nature Methods, vol. 10, no. 10, p. 996-+, 2013.

[33] R. C. Edgar, "MUSCLE: multiple sequence alignment with high accuracy and high throughput," Nucleic Acids Research, vol. 32, no. 5, pp. 1792-1797, 2004.

[34] L. Pan, J. Liu, M. H. Farouk et al., "Anti-nutritional characteristics and mechanism of soybean agglutinin," Biocell, vol. 45, no. 3, pp. 451-459, 2021.

[35] A. L. C. Senedese, R. Maciel Filho, and M. R. W. Maciel, "L-lactic acid production by Lactobacillus rhamnosus ATCC 10863," TheScientificWorldJOURNAL, vol. 2015, pp. 501029-501029, 2015.

[36] J. L. Arques, E. Rodriguez, S. Langa, J. Maria Landete, and M. Medina, "Antimicrobial activity of lactic acid bacteria in dairy products and gut: effect on pathogens," BioMed Research International, vol. 2015, Article ID 584183, 2015.

[37] S. K. Nayak, "Multifaceted applications of probiotic Bacillus species in aquaculture with special reference to Bacillus subtilis," Reviews in Aquaculture, vol. 13, no. 2, pp. 862-906, 2021.

[38] S. Refstie, S. Sahlstrom, E. Brathen, G. Baeverfjord, and P. Krogedal, "Lactic acid fermentation eliminates indigestible carbohydrates and antinutritional factors in soybean meal for Atlantic salmon (Salmo salar)," Aquaculture, vol. 246, no. 14, pp. 331-345, 2005.

[39] L.-C. Zhuo, K. Liu, and Y.-H. Lin, "Apparent digestibility of soybean meal and Lactobacillus spp. fermented soybean meal in diets of grouper, Epinephelus coioides," Aquaculture Research, vol. 47, no. 3, pp. 1009-1012, 2016.

[40] C.-H. Liu, Y.-L. Shiu, and J.-L. Hsu, "Purification and characterization of trypsin from the pyloric ceca of orange-spotted grouper," Epinephelus coioides. Fish Physiology and Biochemistry, vol. 38, no. 3, pp. 837-848, 2012.

[41] J. J. Olli, K. Hjelmeland, and A. Krogdahl, "Soybean trypsin inhibitors in diets for Atlantic salmon (Salmo salar, L): effects on nutrient digestibilities and trypsin in pyloric caeca homogenate and intestinal content," Comparative Biochemistry and Physiology a-Physiology, vol. 109, no. 4, pp. 923-928, 1994.

[42] A. Pavasovic, A. J. Anderson, P. B. Mather, and N. A. Richardson, "Influence of dietary protein on digestive enzyme activity, growth and tail muscle composition in redclaw crayfish, Cherax quadricarinatus (von Martens)," Aquaculture Research, vol. 38, no. 6, pp. 644-652, 2007.

[43] A. K. Ray, K. Ghosh, and E. Ringo, "Enzyme-producing bacteria isolated from fish gut: a review," Aquaculture Nutrition, vol. 18, no. 5, pp. 465-492, 2012.

[44] C. Zhang, S. Rahimnejad, Y. R. Wang et al., "Substituting fish meal with soybean meal in diets for Japanese seabass (Lateolabrax japonicus): effects on growth, digestive enzymes activity, gut histology, and expression of gut inflammatory and transporter genes," Aquaculture, vol. 483, pp. 173-182, 2018.

[45] P. Wang, Q. Zhou, J. Feng, J. He, Y. Lou, and J. Zhu, "Effect of dietary fermented soybean meal on growth, intestinal morphology and microbiota in juvenile large yellow croaker, Larimichthys crocea," Aquaculture Research, vol. 50, no. 3, pp. 748-757, 2019.

[46] R. Novriadi, M. Rhodes, M. Powell, T. Hanson, and D. A. Davis, "Effects of soybean meal replacement with fermented soybean meal on growth, serum biochemistry and morphological condition of liver and distal intestine of Florida pompano Trachinotus carolinus," Aquaculture Nutrition, vol. 24, no. 3, pp. 1066-1075, 2018.

[47] L. G. Buttle, A. C. Burrells, J. E. Good, P. D. Williams, P. J. Southgate, and C. Burrells, "The binding of soybean agglutinin (SBA) to the intestinal epithelium of Atlantic salmon, Salmo salar and rainbow trout, Oncorhynchus mykiss, fed high levels of soybean meal," Veterinary Immunology and Immunopathology, vol. 80, no. 3-4, pp. 237-244, 2001.

[48] M. Gu, N. Bai, W. Xu, H. Zhou, W. Zhang, and K. Mai, "Effects of dietary beta-conglycinin and glycinin on digestive enzymes activities, intestinal histology and immune responses of juvenile turbot Scophthalmus maximus," Aquaculture Research, vol. 47, no. 3, pp. 1001-1008, 2016.

[49] M. Gu, Q. Jia, Z. Zhang, N. Bai, X. Xu, and B. Xu, "Soya-saponins induce intestinal inflammation and barrier dysfunction in juvenile turbot (Scophthalmus maximus)," Fish \& Shellfish Immunology, vol. 77, pp. 264-272, 2018.

[50] E. Ringo, Z. Zhou, J. L. G. Vecino et al., "Effect of dietary components on the gut microbiota of aquatic animals. A neverending story?," Aquaculture Nutrition, vol. 22, no. 2, pp. 219-282, 2016.

[51] N. D. Schwalm II and E. A. Groisman, "Navigating the gut buffet: control of polysaccharide utilization in Bacteroides spp.," Trends in Microbiology, vol. 25, no. 12, pp. 10051015, 2017.

[52] I. Mukhopadhya, R. Hansen, E. M. El-Omar, and G. L. Hold, "IBD-what role do Proteobacteria play?," Nature Reviews Gastroenterology \& Hepatology, vol. 9, no. 4, pp. 219-230, 2012. 
[53] G. Rizzatti, L. R. Lopetuso, G. Gibiino, C. Binda, and A. Gasbarrini, "Proteobacteria: a common factor in human diseases," BioMed Research International, vol. 2017, 2017.

[54] M. Zhang, C. Shan, F. Tan, S. M. Limbu, L. Chen, and Z.Y. Du, "Gnotobiotic models: powerful tools for deeply understanding intestinal microbiota-host interactions in aquaculture," Aquaculture, vol. 517, 2020.

[55] L. Zhao, F. Zhang, X. Ding et al., "Gut bacteria selectively promoted by dietary fibers alleviate type 2 diabetes," Science, vol. 359 , no. 6380 , p. $1151-+, 2018$. 